\title{
Validação intralaboratorial de método quantitativo para determinação múltipla de resíduos de avermectinas em leite bovino por cromatografia líquida de alta eficiência com detecção de fluorescência In-house validation of a multi-residue method for determining residual avermectin in cow's milk by hplc coupled with fluorescence detection
}

\author{
Scheilla Vitorino Carvalho de SOUZA ${ }^{1}$, Josefa Abucáter LIMA², \\ João Carlos TEODORO², Roberto Gonçalves JUNQUEIRA ${ }^{1 *}$
}

\begin{abstract}
Resumo
Um procedimento detalhado para validação intralaboratorial de métodos, incluindo delineamento experimental, estatísticas e avaliação de premissas foi proposto e aplicado à validação de um método para ensaio de avermectinas em leite bovino por cromatografia líquida de alta eficiência com detector de fluorescência. Foram realizados ensaios com curvas de solventes e de matriz, amostras de leite bovino brancas e adicionadas. As premissas relacionadas às estatísticas empregadas foram avaliadas e confirmadas. Linearidade foi obtida entre 25 e 150 ng.mL ${ }^{-1}$. Não foram observados efeitos de matriz significativos nesta faixa. As médias de recuperação aparente variaram de 87,2 a $101,4 \%$. Desvios padrão relativos sob condições de repetitividade estiveram entre 3,3 e 11,2\%, enquanto os desvios padrão relativos de reprodutibilidade parcial foram de 7,4 a 14,7\%. Estes resultados indicaram exatidão e precisão do método entre 10 e $30 \mu \mathrm{g} . \mathrm{L}^{-1}$ para os quatro analitos estudados. Os limites de detecção e quantificação experimentais foram 5 e $10 \mu \mathrm{g} \cdot \mathrm{L}^{-1}$, respectivamente. Limites de decisão $\left(12,6\right.$ a $\left.13,7 \mu \mathrm{g} . \mathrm{L}^{-1}\right)$ e capacidades de detecção (15,1 a 17,4 $\left.\mu \mathrm{g} . \mathrm{L}^{-1}\right)$ foram estimados, assumindo um limite máximo de resíduo de $10 \mu \mathrm{g} . \mathrm{L}^{-1}$.

Palavras-chave: validação intralaboratorial; abamectina; doramectina; eprinomectina; ivermectina; leite bovino; cromatografia líquida de alta eficiência.
\end{abstract}

\begin{abstract}
A detailed procedure for in-house validation of methods, including experimental design, statistics and evaluation of assumptions, was proposed and applied to the validation of a method for screening avermectins in cow's milk by high performance liquid chromatography coupled with fluorescence detection. Assays were performed with solvent and matrix-matched calibration curves, milk blanks and spiked samples. The assumptions about the statistics employed were evaluated and confirmed. Linearity was achieved between 25 and 150 ng.mL ${ }^{-1}$. No significant matrix effects were observed in this range. Mean apparent recoveries varied from 87.2 to $101.4 \%$. The relative standard deviations under conditions of repeatability ranged from 3.3 to $11.2 \%$, while the relative standard deviations of partial reproducibility varied from 7.4 to $14.7 \%$. These results indicated exactness and precision of the method between 10 and $30 \mu \mathrm{g} . \mathrm{L}^{-1}$ for the four analytes studied. The experimental limits of detection and quantification were 5 and $10 \mu \mathrm{g} . \mathrm{L}^{-1}$, respectively. Decision limits (12.6 to $\left.13.7 \mu \mathrm{g} . \mathrm{L}^{-1}\right)$ and detection capabilities ( 15.1 to $17.4 \mu \mathrm{g} . \mathrm{L}^{-1}$ ) were estimated, assuming a maximum residue level of $10 \mu \mathrm{g} . \mathrm{L}^{-1}$.

Keywords: in-house validation; abamectin; doramectin; eprinomectin; ivermectin, cow's milk; high performance liquid chromatography.
\end{abstract}

\section{Introdução}

As avermectinas constituem um importante grupo de agentes antiparasitários amplamente utilizados em bovinos criados para produção de alimentos. Estes compostos são efetivos em doses extremamente baixas contra um grande espectro de nematóides e artrópodes, muitos dos quais são significantes endoparasitas e ectoparasitas de animais ${ }^{9}$.

Apesar do grande número de investigações, o mecanismo de ação das avermectinas ainda não está completamente elucidado. Estes compostos ativam os canais de cloreto dos neurotransmissores inibitórios ácido gama-aminobutírico e glutamato, provocando a paralisia dos parasitas ${ }^{2,12,43}$. Como o mecanismo de ação não é específico, as avermectinas podem afetar organismos não alvos ${ }^{30}$. As avermectinas não apresentam atividades mutagênicas ou carcinogênicas, mas podem

Recebido para publicação em 26/12/2006

Aceito para publicação em 19/7/2007 (002151)

Departamento de Alimentos, Faculdade de Farmácia - FAFAR,

Universidade Federal de Minas Gerais - UFMG,

E-mail: junkeira@netuno.lcc.ufmg.br

2 Laboratório de Referência Agropecuária de Minas Gerais - LANAGRO - MG,

Ministério da Agricultura, Pecuária e Abastecimento - MAPA

* A quem a correspondência deve ser enviada ser embriotóxicas em animais de laboratório ${ }^{6}$. O CODEX ALIMENTARIUS ${ }^{10}$ recomenda limites máximos de resíduos de 10 e $20 \mu \mathrm{g} . \mathrm{L}^{-1}$ para ivermectina (IVE) e eprinomectina (EPR) em leite, respectivamente, não estabelecendo valores de referência para abamectina (ABA) e doramectina (DOR) nesta matriz. No Brasil, o monitoramento de resíduos destas drogas veterinárias em leite é regulamentado pelo Plano Nacional de Controle de Resíduos (PNCRB) ${ }^{6}$, um programa de monitoramento, investigação e fiscalização de resíduos e contaminantes em produtos de origem animal do Ministério da Agricultura, Pecuária e Abastecimento (MAPA). Este programa estabeleceu os limites máximos sugeridos pelo CODEX ALIMENTARIUS ${ }^{10}$ para monitorar resíduos avermectinas em leite bovino.

A confiabilidade dos estudos relativos à presença de resíduos de avermectinas em leite depende crucialmente da eficiência do método de ensaio empregado. Geralmente, os métodos para determinação de avermectinas incluem extração baseada em partição líquido-líquido e purificação por extração em fase sólida. Métodos fundamentados na técnica de cromatografia líquida (CL) com detecção de ultravioleta (UV), fluorescência (FL) e espectrometria de massas (EM) têm sido reportados. Entretanto, as detecções por FL e EM oferecem 
maior sensibilidade e seletividade que os métodos baseados em detecção UV. CL-FL possui um alto grau de especificidade devido à combinação da seletividade cromatográfica e de grupos cromogênicos, além de adequada sensibilidade devido à forte fluorescência dos derivados. CL-FL tem sido preferida também devido à vantagem de ser econômica para uso em atividades de rotina, em detrimento dos altos custos dos métodos que empregam $\mathrm{EM}^{44}$.

A validação de métodos é o processo que fornece evidências de que um dado método de ensaio produz resultados que são adequados para o propósito de uso $^{26}$. Independentemente de quão adequado é o desempenho de um método em um estudo de validação já estabelecido, os analistas necessitam confirmar que o método é válido quando aplicado em seus laboratórios por meio de procedimentos de validação intralaboratoriais. Considerando que processos de validação interlaboratorial principalmente avaliam exatidão e precisão sob condições de repetitividade e reprodutibilidade ${ }^{19}$, validações intralaboratoriais são também essenciais para determinação de parâmetros de desempenho como linearidade, efeitos de matriz, seletividade e limites.

Diversos procedimentos de validação intralaboratorial são descritos na literatura ${ }^{14-16,20,21,32,42}$. Embora nestes documentos haja concordância sobre quais parâmetros devam ser avaliados, existe uma grande diversidade e até falta de informações sobre como estes experimentos são delineados e avaliados em termos de estatísticas e respectivas premissas que necessitam ser testadas.

Considerando que processos de validação incompletos ou equivocados são importantes fontes de erro em análises de alimentos, o presente trabalho apresenta um procedimento detalhado para validação intralaboratorial, aplicado a um método quantitativo para ensaio de ABA, DOR, EPR e IVE em leite por cromatografia líquida de alta eficiência com detecção de fluorescência (CLAE-FL).

\section{Material e métodos}

\subsection{Soluções}

\section{Solução padrão de $A B A$}

A solução estoque de ABA de $10 \mu \mathrm{g} \cdot \mathrm{mL}^{-1}$ foi preparada por dissolução de 60,6 \ 0,1 mg do padrão de ABA 0,819\% m.m ${ }^{-1}$ Bla (Merck, Darmstadt, Alemanha) para $50 \mathrm{~mL}$ de metanol grau CLAE (Vetec, Rio de Janeiro, Brasil). Esta solução foi armazenada sob congelamento entre $-14 \mathrm{e}-20{ }^{\circ} \mathrm{C}$ e preparada em freqüência anual.

\section{Soluções padrão de DOR}

A solução estoque de DOR de $100 \mu \mathrm{g} \cdot \mathrm{mL}^{-1}$ foi preparada por dissolução de 10,4 \pm 0,1 mg do padrão de DOR 95,6\% (Pfizer, Groton, EUA) para $100 \mathrm{~mL}$ de metanol grau CLAE (Vetec, Rio de Janeiro, Brasil). Uma solução intermediária de $10 \mu \mathrm{g} \cdot \mathrm{mL}^{-1}$ foi preparada por diluição de $10 \mathrm{~mL}$ da solução estoque para $100 \mathrm{~mL}$ com metanol grau CLAE (Vetec, Rio de Janeiro, Brasil).
Estas soluções foram armazenadas sob congelamento entre -14 e $-20{ }^{\circ} \mathrm{C}$ e preparadas em freqüência anual e semestral, respectivamente.

\section{Soluções padrão de EPR}

A solução estoque de EPR de $100 \mu$ g. $\mathrm{mL}^{-1}$ foi preparada por dissolução de 10,30 \pm 0,1 mg do padrão de EPR 97,3\% (Merck, Darmstadt, Alemanha) para $100 \mathrm{~mL}$ de metanol grau CLAE (Vetec, Rio de Janeiro, Brasil). Uma solução intermediária de $10 \mu \mathrm{g} \cdot \mathrm{mL}^{-1}$ foi preparada por diluição de $10 \mathrm{~mL}$ da solução estoque para $100 \mathrm{~mL}$ com metanol grau CLAE (Vetec, Rio de Janeiro, Brasil). Estas soluções foram armazenadas sob congelamento entre $-14 \mathrm{e}-20{ }^{\circ} \mathrm{C}$ e preparadas em freqüência anual e semestral, respectivamente.

\section{Solução padrão de IVE}

A solução estoque de IVE de $10 \mu \mathrm{g} \cdot \mathrm{mL}^{-1}$ foi preparada por dissolução de 35,95 mg \pm 0,1 mg do padrão de IVE 1,39\% m.m ${ }^{-1}$ H2B1a (Merck, Darmstadt, Alemanha) para $50 \mathrm{~mL}$ de metanol grau CLAE (Vetec, Rio de Janeiro, Brasil). Esta solução foi armazenada sob congelamento entre $-14 \mathrm{e}-20{ }^{\circ} \mathrm{C}$ e preparada em freqüência anual.

\section{Solução padrão de adição pool de ABA, DOR, EPR e IVE}

A solução de adição pool das avermectinas de 250 ng.mL ${ }^{-1}$ foi preparada por diluição de $5 \mathrm{~mL}$ da solução estoque de ABA, $5 \mathrm{~mL}$ da solução intermediária de DOR, $5 \mathrm{~mL}$ da solução intermediária de EPR e $5 \mathrm{~mL}$ da solução estoque de IVE para $200 \mathrm{~mL}$ de metanol grau CLAE (Vetec, Rio de Janeiro, Brasil). Esta solução foi armazenada sob congelamento entre -14 e $-20{ }^{\circ} \mathrm{C}$ e preparada em freqüência semestral.

\section{Solução de derivação}

Foram misturados $200 \mu \mathrm{L}$ de 1-metilimidazol grau para análise (Acros Organic, New Jersey, EUA) a $600 \mu \mathrm{L}$ de anidrido acético grau para análise (Fisher, New Jersey, EUA) e $900 \mu \mathrm{L}$ de N,N-dimetilformamida grau para análise (Fisher, New Jersey, EUA) e homogeneizados. Esta solução foi preparada imediatamente antes de cada uso.

\section{Solução de extração}

Foram misturados $700 \mathrm{~mL}$ de água destilada e deionizada com $300 \mathrm{~mL}$ de acetonitrila grau CLAE (Vetec, Rio de Janeiro, Brasil) e $1 \mathrm{~mL}$ de trietilamina grau para análise (Merck, Darmstadt, Alemanha).

\subsection{Amostras}

Amostras brancas de leite bovino foram obtidas de ordenhas de animais sabidamente não tratados com avermectinas na fazenda experimental do Ministério da Agricultura, Pecuária e Abastecimento (MAPA) - Escola de Veterinária da UFMG, na cidade de Pedro Leopoldo (Minas Gerais, Brasil).

As amostras foram homogeneizadas, acondicionadas em frascos de vidro com tampa de rosca devidamente identifica- 
dos e armazenadas sob congelamento entre -14 e $-20^{\circ} \mathrm{C}$, até o momento dos ensaios.

\subsection{Método de ensaio}

O método validado foi baseado em procedimentos previamente descritos ${ }^{34,36,40}$ e fundamentou-se na extração de resíduos de ABA, DOR, EPR e IVE do leite com uma mistura acetonitrila:água destilada e deionizada:trietilamina, seguida de purificação do extrato e eluição das avermectinas em cartucho de C-18 com acetonitrila. Após a derivação, o extrato foi solubilizado em metanol e os resíduos foram separados dos componentes co-extraídos, detectados e quantificados por CLAE com detector FL.

\section{Extração}

As amostras de leite foram descongeladas e homogeneizadas. Alíquotas de $5 \mathrm{~mL} \pm 5 \%$ foram pipetadas e transferidas para tubos de centrífuga de $50 \mathrm{~mL}$ de polipropileno, sendo adicionados $20 \mathrm{~mL}$ da solução de extração. Os tubos foram colocados em agitador mecânico horizontal (Ebberbach) ajustado na velocidade máxima por 5 minutos. Os extratos homogeneizados foram aquecidos em banho-maria (Yamato) a $40 \pm 5{ }^{\circ} \mathrm{C}$, sob agitação, para completa dissolução da gordura. Brancos de solventes, sem adição de amostra, foram preparados em cada bateria analítica.

\section{Acondicionamento dos cartuchos de extração em fase sólida}

Os cartuchos de extração adaptados aos reservatórios tipo seringa de $50 \mathrm{~mL}$ foram conectados ao sistema de vácuo (Varian Vac Elut). Em seguida, foram lavados com $5 \mathrm{~mL} \pm 5 \%$ de acetonitrila grau CLAE (Vetec, Rio de Janeiro, Brasil) e com $5 \mathrm{~mL} \pm 5 \%$ da solução de extração, sob fluxo de $0,3 \mathrm{~mL} \cdot \mathrm{min}^{-1}$.

\section{Purificação}

Os extratos de amostras e brancos de solventes foram transferidos para os reservatórios tipo seringas adaptados aos cartuchos de extração em fase sólida, com auxílio de pipetas tipo Pasteur, a um fluxo de 0,3 mL. $\mathrm{min}^{-1}$. Os reservatórios e cartuchos foram lavados com $5 \mathrm{~mL} \pm 5 \%$ da solução de extração, deixados secar, e novamente lavados com $2 \mathrm{~mL} \pm 5 \%$ de hexano grau para análise (Merck, Darmstadt, Alemanha), sob fluxo de $0,3 \mathrm{~mL} \cdot \mathrm{min}^{-1}$. Os resíduos das avermectinas foram eluídos com $5 \mathrm{~mL} \pm 5 \%$ de acetonitrila grau CLAE (Vetec, Rio de Janeiro, Brasil) para tubos de $10 \mathrm{~mL}$ de vidro, sob fluxo da gravidade. Os extratos purificados foram evaporados até secura em banho-maria (Yamato) a $60 \pm 5{ }^{\circ} \mathrm{C}$, sob agitação e fluxo de nitrogênio.

\section{Preparo da curva de calibração}

Alíquotas da solução padrão de adição foram pipetadas e transferidas para tubos de $10 \mathrm{~mL}$ de vidro. As soluções foram evaporadas até secura em banho-maria (Yamato) a $45 \pm 5{ }^{\circ} \mathrm{C}$, sob agitação e fluxo de nitrogênio.

\section{Derivação}

Os resíduos (de amostras e de soluções padrão da curva de calibração) foram retomados com $200 \mu \mathrm{L} \pm 2 \%$ da solução de derivação. Os tubos foram fechados, homogeneizados em agitador tipo Vortex Mixer (Sybron Thermoline) durante 30 segundos e colocados em chapa aquecedora (Kontes) entre 90 e $100{ }^{\circ} \mathrm{C}$ durante 1 hora. Após resfriamento à temperatura ambiente, os resíduos derivados foram retomados em $1000 \mu \mathrm{L} \pm 2 \%$ de metanol e filtrados através de filtros de $0,45 \mu \mathrm{m}$ para frascos de $2 \mathrm{~mL}$.

\section{Separação, detecção e quantificação}

O cromatógrafo líqüido de alta eficiência Gilson (Villiers le Bel, França) era composto pelos seguintes módulos: bomba isocrática tipo CG-305, injetor manual Rheodyne 7125 com loop de $20 \mu \mathrm{L}$, detector de fluorescência tipo CG-432 FL, sistema de aquisição de dados e integrador CG-300.

As condições de operação do sistema CLAE-FL foram: volume de injeção de $20 \mu \mathrm{L}$; fase móvel composta por metanol grau CLAE (Vetec, Rio de Janeiro, Brasil); sistema isocrático; fluxo de 0,9 mL.min ${ }^{-1}$; comprimento de onda de excitação e emissão de $366 \mathrm{~nm}$ e $426 \mathrm{~nm}$, respectivamente; tempo total de corrida de 12 minutos; e integração pelo parâmetro altura dos picos.

Curvas de calibração da resposta (altura dos picos) versus a concentração de cada avermectina foram construídas. As equações das curvas foram estimadas pelo método dos mínimos quadrados ordinários (MMQO) e utilizadas para cálculo da concentração de avermectinas nas amostras.

\subsection{Validação}

Os parâmetros linearidade, efeitos de matriz, seletividade, exatidão, precisão, limite de detecção, limite de quantificação, limite de decisão $(C C \alpha)$ e capacidade de detecção $(C C \beta)$ foram estabelecidos em ensaios com soluções padrão, amostras brancas e adicionadas. A adequação para uso do método foi avaliada em função dos parâmetros estudados e respectivos critérios de aceitabilidade definidos.

\section{Linearidade}

Linearidade foi avaliada conforme procedimento descrito por SOUZA e JUNQUEIRA ${ }^{39}$. Três curvas de calibração foram preparadas, em diferentes dias, com níveis de concentração 25; 50; 75; 100; 125 e 150 ng. $\mathrm{mL}^{-1}$ (correspondentes a 5; 10; 15; 20; 25 e $30 \mu \mathrm{g} . \mathrm{L}^{-1}$ de cada avermectina em leite bovino), sendo três replicatas independentes de cada nível. Alíquotas de 100; 200; 300; 400; 500 e $600 \mu \mathrm{L}$, respectivamente, da solução padrão pool de adição foram utilizadas para preparo destas curvas conforme descrito no método de ensaio. As soluções foram analisadas em ordem aleatória dentro de cada dia. Brancos foram preparados, em triplicata, para todas as curvas como ferramenta de controle interno de qualidade para ajuste do zero do equipamento, mas não foram incluídos nos cálculos. 
Os parâmetros da regressão foram estimados pelo MMQO aplicado ao modelo linear $\left(Y_{i}=a+b X_{i}\right)$, em que $Y_{i}$ representa as respostas (altura dos picos), $X_{i}$ as concentrações dos padrões dos analitos, $a$ e $b$ estimativas dos parâmetros da equação. Em seguida, gráficos dos resíduos $\left(Y_{i}-a-b X_{i}\right)$ da regressão foram construídos e examinados para investigação de perfis óbvios que demonstrassem heteroscedasticidade ou desvio de linearidade, sendo indicados como outliers (valores extremos) os pontos fora do intervalo $\pm t_{(0,975 ; n-2)} s_{\text {res }}$, baseado no método proposto por MEYER e ZUND ${ }^{31}$. Os outliers foram formalmente diagnosticados pelo teste de resíduos padronizados Jacknife ${ }^{5}$. Este teste foi aplicado sucessivamente até que novos outliers não fossem detectados ou até uma exclusão máxima de $22,2 \%$ no número original de resultados ${ }^{19}$. As premissas relativas à análise de regressão foram verificadas: normalidade $^{35}$, homoscedasticidade ${ }^{7,28}$ e independência dos resíduos da regressão ${ }^{13}$. Testes de $F$ foram adotados para verificar a adequação do ajuste ao modelo linear por meio das significâncias da regressão e do desvio de linearidade avaliado contra o erro puro ${ }^{11}$.

\section{Efeitos de matriz}

O método de adição foi empregado para avaliação dos efeitos de matriz. Duas curvas de calibração foram estudadas em níveis de 25; 50; 75; 100; 125 e 150 ng.mL m $^{-1}$, sendo cada nível em duas replicatas independentes, analisadas em ordem aleatória, no mesmo dia. A curva do analito no solvente (metanol) foi preparada conforme descrito nos experimentos de avaliação da linearidade. Para a curva do analito na matriz utilizaram-se extratos purificados de amostras brancas de leite bovino adicionados de 100; 200; 300; 400; 500 e $600 \mu \mathrm{L}$ da solução padrão pool de adição. Brancos foram preparados para cada curva e utilizados como ferramenta de controle interno de qualidade para ajuste do zero do equipamento, mas não foram incluídos nos cálculos.

Os parâmetros da regressão foram estimados e as premissas relativas ao MMQO também foram verificadas para estas curvas. Uma vez comprovadas as premissas de normalidade a ajuste ao modelo linear, a inclinação e a interseção obtidas para a curva de solventes foram comparadas com a inclinação e interseção calculadas para a curva de matriz. A premissa de homogeneidade das variâncias dos resíduos das curvas foi avaliada pelo teste de $F^{38}$, para verificar se inclinações e interseções seriam comparadas pelo teste de $t$ com as variâncias combinadas $^{3}$.

\section{Seletividade, exatidão e precisão}

Seletividade, exatidão, precisão (sob condições de repetitividade e reprodutibilidade parcial), limites de detecção e quantificação, $C C \alpha$ e $C C \beta$ foram pesquisados em ensaios com amostras brancas e adicionadas em níveis correspondentes a $5 ; 10 ; 15 ; 20$ e $30 \mu$ g. $\mathrm{kg}^{-1}$, sendo doze replicatas independentes de cada nível. As amostras foram divididas em quatro lotes com três replicatas de cada nível, analisados em quatro diferentes dias por dois analistas: dias 1 e 2 pelo analista 1 e dias 3 e 4 pelo analista 2 . As concentrações de avermectinas nas amostras adicionadas foram preditas pelas equações das curvas de calibração de solventes, com base nos resultados dos estudos de efeitos de matriz.

A ausência de resultados falsos positivos para todas as amostras brancas, associada à capacidade do método separar, detectar e quantificar os quatro resíduos de avermectinas (ABA, DOR, EPR e IVE) sem interferência mútua, foi considerada suficiente para estabelecimento da seletividade.

Os resultados de recuperação aparente obtidos foram analisados quanto à presença de outliers pelo teste de Grubbs ${ }^{4,8,17}$. As estatísticas de Grubbs para um outlier $\left(G_{1}\right)$, dois outliers vicinais $\left(G_{2}\right)$ e dois outliers polares $\left(G_{3}\right)$ foram calculadas simultaneamente para os resultados obtidos para cada nível de concentração. A indicação de outlier por, pelo menos, uma destas estatísticas seria suficiente para excluir o dado. Após um primeiro ciclo, o teste de Grubbs era sucessivamente aplicado até que novos outliers não fossem detectados ou até uma exclusão máxima de $22,2 \%$ no número original de resultados de recuperação aparente ${ }^{19}$.

Exatidão foi investigada por meio das médias de recuperação aparente obtida para as doze replicatas de amostras adicionadas em cada nível de concentração. Foram consideradas aceitáveis médias de recuperação aparente entre 70 e $110 \%$ para amostras adicionadas de $5 \mu \mathrm{g} . \mathrm{L}^{-1}$ e de 80 a $110 \%$ para as amostras adicionadas nos níveis de $10 ; 15 ; 20$ e $30 \mu \mathrm{g} . \mathrm{L}^{-1} 15$.

As precisões sob condições de repetitividade e reprodutibilidade parcial (precisão intermediária) foram expressas em termos de desvios padrão relativos e estimadas por análise de variância dos resultados de recuperação aparente obtidos para as doze replicatas de amostras adicionadas em cada nível de concentração ${ }^{22,23,27}$. Foi adotado um delineamento fatorial completamente aninhado (fully-nested design) que forneceu as estimativas da variância de repetitividade $\left(s_{r}^{2}\right)$; da variância do ensaio $\left(s^{2}{ }_{\text {ensaio }}\right)$, que incluiu as fontes de variação confundidas do dia e do analista (dia + analista); da variância entre ensaios $\left[s^{2}{ }_{\text {entre ensaios }}=\left(s^{2}{ }_{\text {ensaio }}-s^{2}{ }_{r}\right) / n\right.$ ], sendo $n$ o número médio de replicatas em cada nível de concentração; e da variância de reprodutibilidade parcial $\left(s_{R}^{2}=s_{r}^{2}+s^{2}{ }_{\text {entre ensaios }}\right)^{29}$. Quando a estimativa da variância de repetitividade era maior que a variância do ensaio, $s^{2}$ entre ensaios era considerada como sendo igual a zero, evitando a obtenção de um valor negativo para a estimativa desta variância ${ }^{22,27}$. Neste caso, as estimativas das variâncias de repetitividade e de reprodutibilidade parcial eram consideradas equivalentes.

As premissas de normalidade ${ }^{35}$ e homoscedasticidade dos resíduos dos resultados de recuperação aparente ${ }^{7,28}$, relativas à análise de variância, foram previamente testadas. Desvios padrão relativos de repetitividade $\left(D P R_{r}\right)$ foram considerados aceitáveis quando inferiores a dois terços ${ }^{15}$ do valor de precisão interlaboratorial estimado pela equação de HORWITZ ${ }^{18}$ modificada por THOMPSON ${ }^{41}$. Já os desvios padrão de reprodutibilidade parcial $\left(D P R_{R}\right)$ foram considerados aceitáveis quando não excederam ao valor estimado pelas equações de HORWITZ $^{18}$ e THOMPSON ${ }^{41}$. Desta forma, $D P R_{r}$ e $D P R_{R}$ menores ou iguais a 14,7 e $22 \%$, respectivamente, foram os critérios de aceitabilidade adotados. 


\section{Limites de detecção e quantificação, $C C \alpha$ e $C C \beta$}

O limite de quantificação foi estabelecido como a concentração abaixo da qual o método não pôde operar com exatidão e precisão aceitáveis. O limite de detecção foi a menor concentração detectada nas amostras adicionadas, mas não necessariamente quantificada, distinguida de zero ( sinal/ruído $\geq 3$ ). Estes limites foram estabelecidos com base nos resultados médios de recuperação aparente e desvios padrão relativos de repetitividade e reprodutibilidade parcial obtidos para as replicatas de amostras adicionadas nos diferentes níveis de concentração estudados.

$C C \alpha$ e $C C \beta$ foram estimados ${ }^{24,25,45}$ utilizando as concentrações estimadas e as respectivas concentrações teóricas das amostras adicionadas dos experimentos de avaliação da reprodutibilidade parcial $^{15}$. O limite máximo de resíduo de $10 \mu \mathrm{g} . \mathrm{L}^{-1}$ foi adotado para o cálculo destes parâmetros para ABA, DOR, EPR e IVE.

\section{Resultados e discussão}

Os perfis dos gráficos de resíduos apresentados nas Figuras 1 e 2 demonstraram que não houve tendências óbvias que demonstrassem heteroscedasticidade ou desvios de linearidade. Os intervalos de confiança dos resíduos $\left( \pm t_{(0,975 ; n-2)} s_{r e s}\right)$ sugeriram a presença de zero a quatro outliers nestes gráficos, que foram confirmados pelo teste de resíduos padronizados Jacknife. Em nenhum caso houve indicação de um número maior que quatro outliers para cada curva, correspondente ao limite máximo de $22,2 \%$ dos dezoito dados originais.

Os resultados obtidos nos experimentos para avaliação da linearidade para ABA, DOR, EPR e IVE estão demonstrados nas Tabelas 1, 2, 3 e 4, respectivamente. As premissas de que os resíduos da regressão seguem a distribuição normal, são homoscedásticos e independentes, foram confirmadas, garantindo uma aplicação segura dos testes de hipóteses de $t$ e $F$, além do emprego adequado da análise de variância sem ponderações para estimativa da significância da regressão e do desvio da linearidade. Os coeficientes de correlação de Ryan-Joiner indicaram que os desvios da normalidade não foram significativos ( $\mathrm{p}>0,10$ ). A variância dos erros ao longo dos níveis de concentração estimada pelo teste de Levene modificado também não foi significativa ( $p>0,05)$, sugerindo homoscedasticidade. Autocorrelação dos resíduos da regressão não foi observada $(\mathrm{p}>0,10)$, visto que as estatísticas de Durbin-Watson demonstraram independência dos mesmos. Os dados obtidos foram avaliados como bem ajustados ao modelo linear. Significância da regressão ( $p<0,001)$ e desvios de linearidade não significativos ( $\mathrm{p}>0,05)$ determinaram linearidade na faixa de 25 a 150 ng. $\mathrm{mL}^{-1}$ para as curvas 1,2 e 3 das quatro avermectinas examinadas.

O uso de critérios equivocados como o coeficiente de correlação $(r)^{42}$ é predominante na avaliação da linearidade de métodos para determinação de avermectinas, assim como a omissão de estudos de efeitos de matriz. POLLMEIER et al. ${ }^{33}$ obtiveram linearidade de um método para ensaio de EPR em leite bovino por CLAE-FL na faixa de 2,3 a 51 ng. $\mathrm{mL}^{-1}$, utilizando amostras adicionadas. ROUDAUT ${ }^{34}$ também determinou linearidade empregando CLAE-FL para ABA, DOR, IVE e moxidectina (MOX), utilizando amostras de fígado bovino adicionadas na faixa de 7,5 a $200 \mu \mathrm{g} . \mathrm{kg}^{-1}$. WU et al. ${ }^{47}$ estabeleceram linearidade para ABA e IVE por CLAE-EM na faixa de 10 a 500 ng. $\mathrm{mL}^{-1}$, enquanto SALISBURY ${ }^{36}$ estudou IVE por CLAE-FL entre 25 e 150 ng. $\mathrm{mL}^{-1}$, ambos empregando curvas de solventes.

As curvas de solventes e de matriz, com respectivas equações e coeficientes de determinação, obtidas nos estudos de efeitos de matriz estão apresentadas na Figura 3. Pelo teste de resíduos padronizados Jacknife foram detectados: um outlier na curva de solventes ( 150 ng. $\mathrm{mL}^{-1}$ ) e dois outliers na curva de matriz (50 e 150 ng.mL (1) $^{-1}$ para ABA; dois outliers na curva de solventes ( 100 e 150 ng.mL ${ }^{-1}$ ) e um outlier na curva de matriz (150 ng. $\mathrm{mL}^{-1}$ ) para DOR e EPR; e dois outliers na curva de solventes ( 100 e 150 ng. $\mathrm{mL}^{-1}$ ) e dois outliers na curva de matriz (75 e 150 ng. $\mathrm{mL}^{-1}$ ) para IVE. Todas as premissas relativas ao MMQO também foram ratificadas para as curvas de solventes e matriz dos quatros analitos. Distribuição normal dos resíduos da regressão foi observada pelos coeficientes de correlação de Ryan-Joiner. Homoscedasticidade foi obtida com estatísticas $t$ de Levene não significativas ( $p>0,05$ ). Independência dos resíduos da regressão foi indicada pelas estatísticas de DurbinWatson $(\mathrm{p}>0,10)$. Regressões significativas $(\mathrm{p}<0,001)$ e desvios de linearidade não significativos $(p>0,05)$ foram diagnosticados pelos testes de $F$ da análise de variância. Estes resultados de confirmação do modelo linear permitiram a comparação das inclinações e interseções pelo teste de $t$ para avaliação dos efeitos de matriz.

O teste de $F$ indicou homogeneidade das variâncias dos resíduos das curvas de solventes e matrizes e a possibilidade do uso do teste de $t$ com variâncias combinadas para avaliação dos efeitos de matriz. Assim, não houve diferenças significativas ( $p>0,05$ ) quando as inclinações e interseções das curvas de solventes foram comparadas com aquelas estimadas para as curvas de matriz para ABA, DOR, EPR e IVE (Tabela 5). Com base nestes resultados, foi possível inferir que curvas de solventes de ABA, DOR, EPR e IVE forneceram as mesmas respostas que amostras de leite contendo as avermectinas estudadas nas mesmas faixas de concentração.

Cromatogramas típicos obtidos para soluções padrão de avermectinas, amostras brancas e amostras adicionadas encontram-se apresentados na Figura 4, demonstrando seletividade do método. Os tempos de retenção médios observados foram de 8,37 $\pm 0,37$ minutos para ABA, 9,83 $\pm 0,46$ minutos para DOR, 6,79 \pm 0,26 minutos para EPR e 11,17 $\pm 0,56 \mathrm{mi}-$ nutos para IVE. Resultados não detectados (sinal/ruído < 3) foram obtidos para todas as amostras brancas analisadas, não havendo interferências significativas nos tempos de retenção para as avermectinas pesquisadas. Os perfis dos cromatogramas obtidos para amostras adicionadas foram indistinguíveis daqueles obtidos para as soluções padrão de avermectinas de concentrações correspondentes. A resolução dos picos indicou capacidade do método em determinar ABA, DOR, EPR e IVE sem interferências mútuas.

O teste de Grubbs não demonstrou a presença de outliers ( $p>0,05)$ entre os resultados de recuperação aparente obtidos para amostras adicionadas dos quatro analitos em todos os 

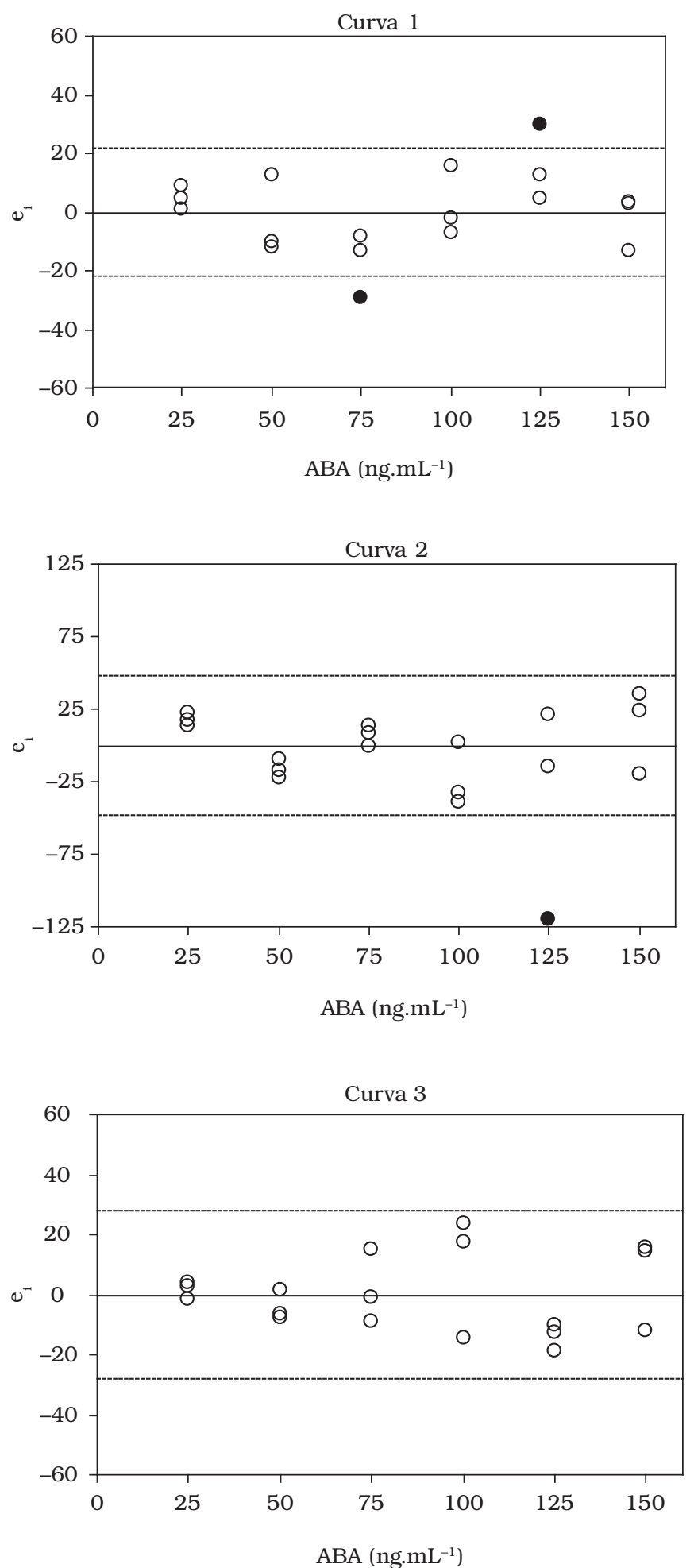

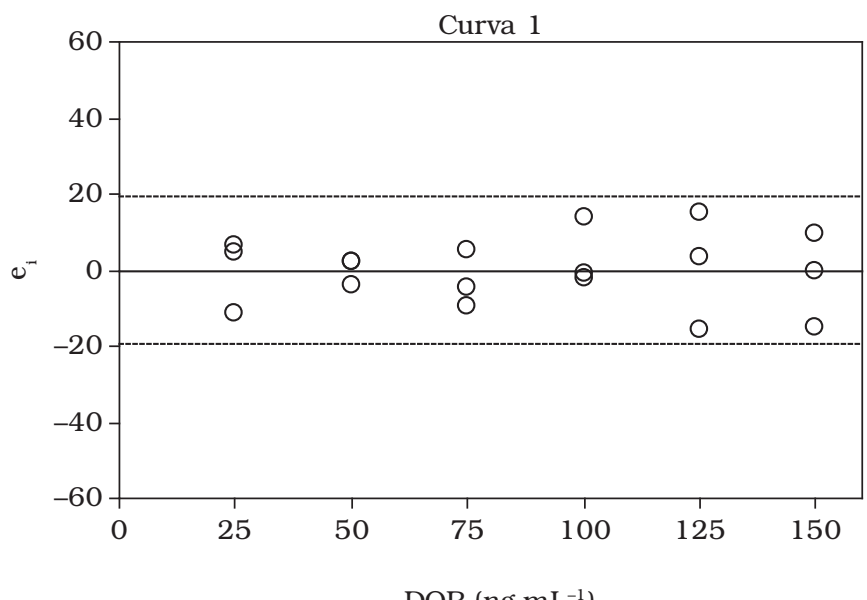

DOR (ng.mL ${ }^{-1}$ )

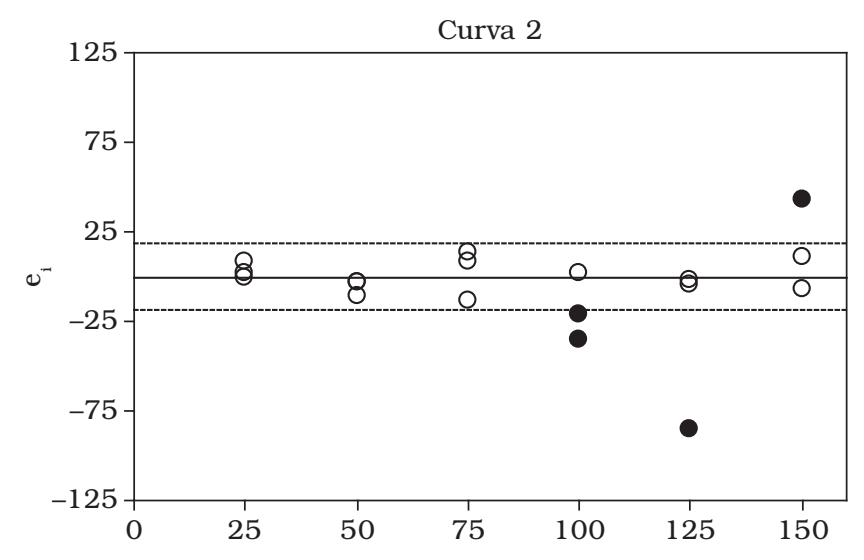

DOR (ng. $\mathrm{mL}^{-1}$ )

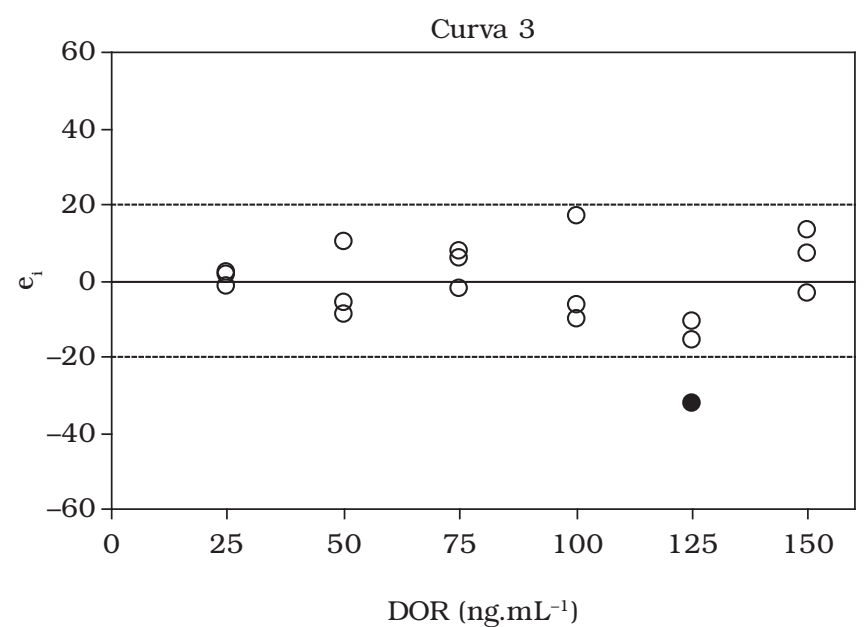

Figura 1. Gráficos dos resíduos da regressão das três curvas de solventes de ABA e DOR (25 a 150 ng.mL -1 $^{-1}$, com indicação dos respectivos outliers diagnosticados pelo teste de resíduos padronizados Jacknife. $\mathrm{e}_{\mathrm{i}}=$ resíduo da regressão; $\bullet=$ outlier; $\mathrm{e}-\cdots-\boldsymbol{-}=\left( \pm t_{(0,975 ; n-2)} \mathrm{s}_{\mathrm{res}}\right)$.

níveis de concentração estudados. Os resíduos, obtidos pela diferença entre a recuperação aparente média e os valores individuais de recuperação aparente obtidos em cada dia, para cada nível de concentração, apresentaram distribuição normal
( $\mathrm{p}>0,10)$ e homoscedasticidade $(\mathrm{p}>0,05)$, permitindo a estimativa de $D P R_{r}$ e $D P R_{R}$ por análise de variância.

As médias de recuperação aparente alcançadas para amostras adicionadas entre 5 e $30 \mu \mathrm{g} . \mathrm{L}^{-1}$ variaram entre 98,1 e 


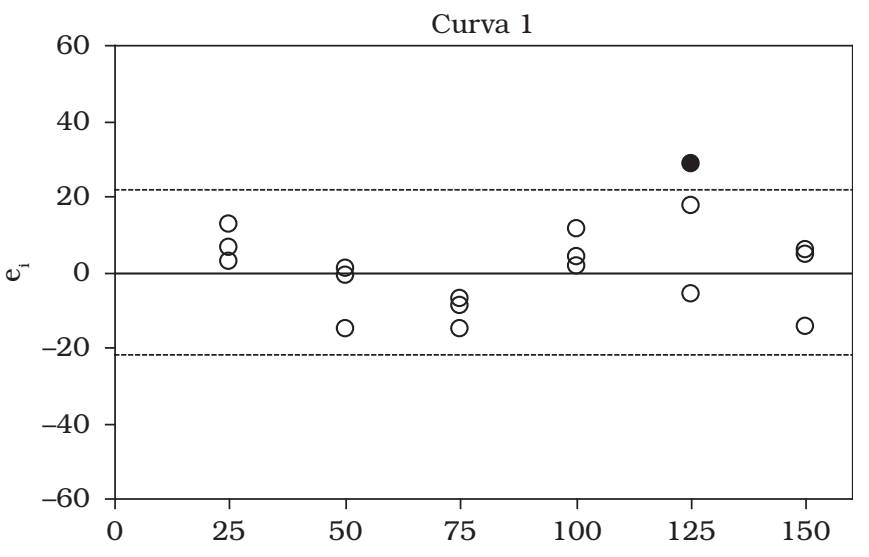

EPR (ng. $\mathrm{mL}^{-1}$ )

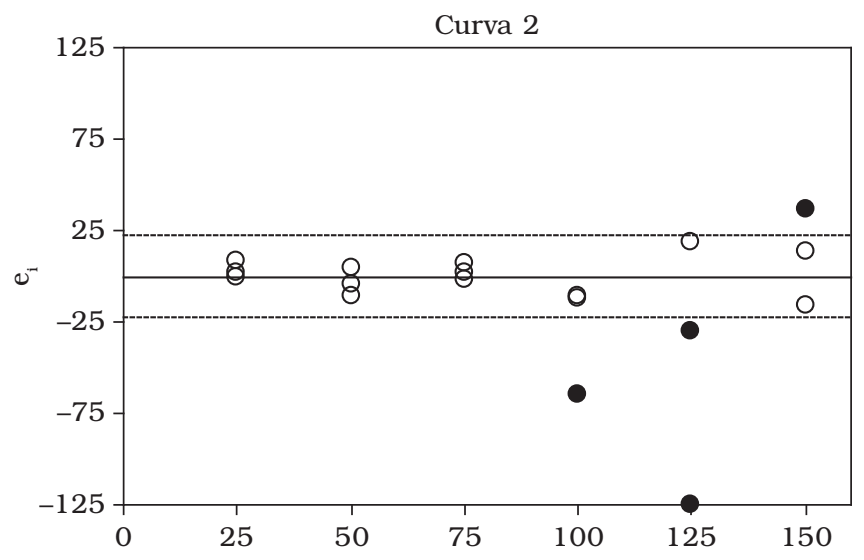

EPR (ng. mL ${ }^{-1}$ )

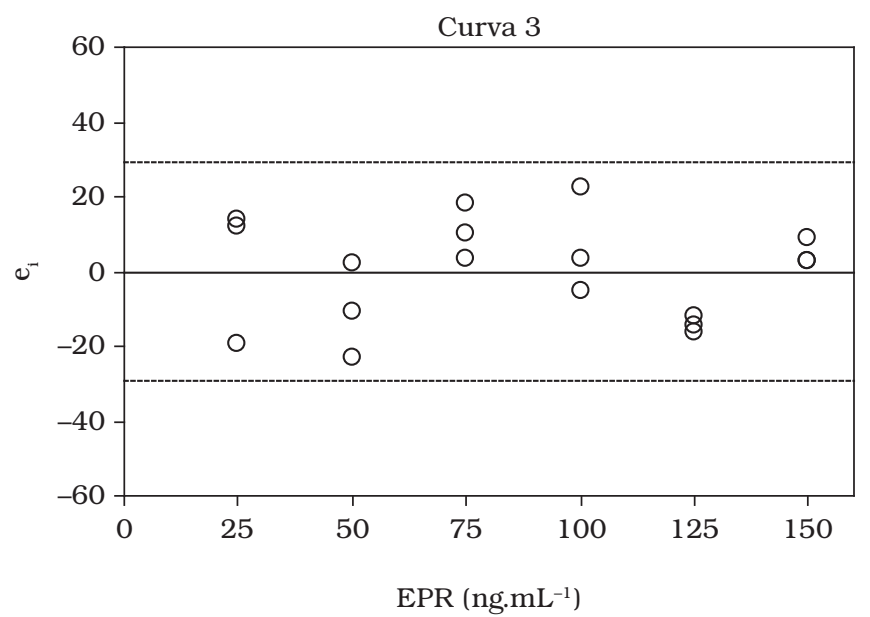

EPR (ng.mL ${ }^{-1}$ )

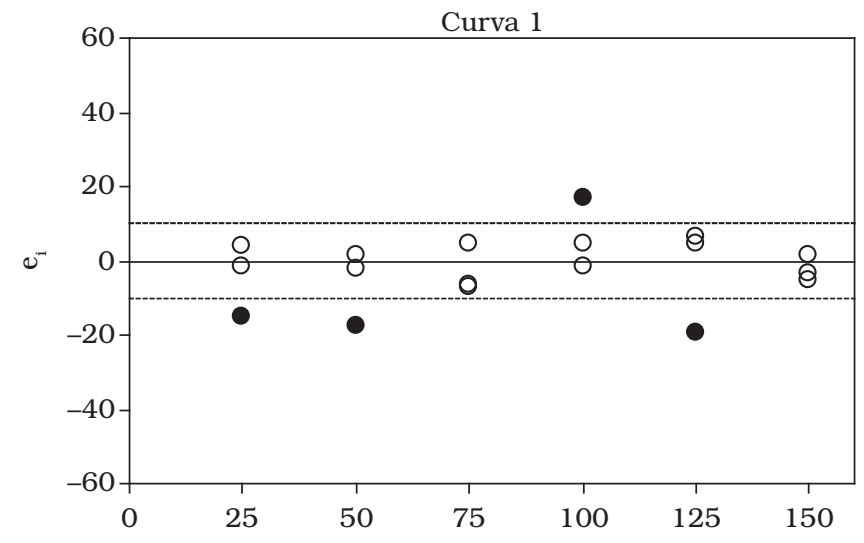

IVE (ng.mL ${ }^{-1}$ )

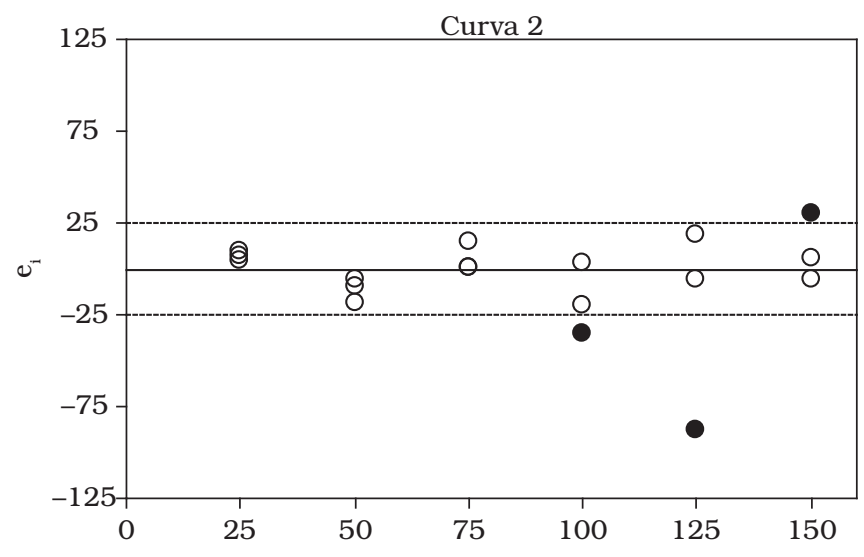

IVE (ng. $\mathrm{mL}^{-1}$ )

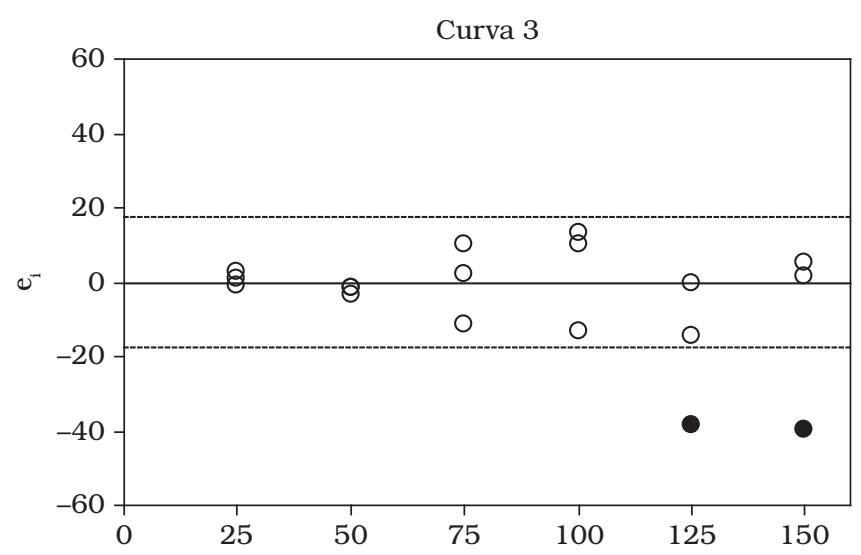

IVE (ng. $\mathrm{mL}^{-1}$ )

Figura 2. Gráficos dos resíduos da regressão das três curvas de solventes de EPR e IVE (25 a 150 ng. $\left.\mathrm{mL}^{-1}\right)$, com indicação dos respectivos outliers diagnosticados pelo teste de resíduos padronizados Jacknife. $\mathrm{e}_{\mathrm{i}}=$ resíduo da regressão; $\bullet=$ outlier; e - - - $=\left( \pm t_{(0,975 ; n-2)} \mathrm{s}_{\text {res }}\right)$.

$101,8 \%$ para ABA; 86,2 e $98 \%$ para DOR; 81,2 e $96,9 \%$ para EPR; e 84 e $94,8 \%$ para IVE. Os $D P R_{r}$ foram de 4,1 a $13,9 \%$ para ABA; de 3,6 a 21,3\% para DOR; de 5 a 20,2\% para EPR; e de 4,4 a $16,7 \%$ para IVE. Os valores de $D P R_{R}$ estiveram entre
8 e $14,3 \%$ para ABA; 8,7 e $21,4 \%$ para DOR; 7,4 e $20,2 \%$ para EPR; e 10,2 e 19,5\% para IVE (Tabelas 6 e 7). Valores de $D P R_{r}$ e $D P R_{R}$ idênticos foram estimados para EPR no nível de $5 \mu \mathrm{g} . \mathrm{L}^{-1}$, uma vez que a estimativa da variância de repetitividade foi 
Tabela 1. Avaliação da linearidade para as três curvas de ABA ( 25 a 150 ng. $\mathrm{mL}^{-1}$ ) em solventes.

\begin{tabular}{|c|c|c|c|}
\hline Estatística & Curva 1 & Curva 2 & Curva 3 \\
\hline \multicolumn{4}{|l|}{ Número de observações } \\
\hline$n$ & 16 & 17 & 18 \\
\hline \multicolumn{4}{|l|}{ Normalidade } \\
\hline$R$ & 0,9754 & 0,9849 & 0,9740 \\
\hline$p$ & $\mathrm{p}>0,10$ & $\mathrm{p}>0,10$ & $\mathrm{p}>0,10$ \\
\hline \multicolumn{4}{|l|}{ Homoscedasticidade } \\
\hline$t_{L}$ & 0,690 & $-1,959$ & $-1,975$ \\
\hline$p$ & $\mathrm{p}>0,05$ & $\mathrm{p}>0,05$ & $\mathrm{p}>0,05$ \\
\hline \multicolumn{4}{|l|}{ Independência } \\
\hline$d$ & 2,139 & 1,803 & 1,525 \\
\hline$p$ & $\mathrm{p}>0,10$ & $\mathrm{p}>0,10$ & $\mathrm{p}>0,10$ \\
\hline \multicolumn{4}{|l|}{ Regressão } \\
\hline$F$ & $2,435 \times 10^{+3}$ & $3,870 \times 10^{+2}$ & $1,886 \times 10^{+3}$ \\
\hline$p$ & $\mathrm{p}<0,001$ & $\mathrm{p}<0,001$ & $\mathrm{p}<0,001$ \\
\hline \multicolumn{4}{|l|}{ Desvio da linearidade } \\
\hline$F$ & 1,365 & 3,169 & 1,715 \\
\hline$p$ & $\mathrm{p}>0,05$ & $\mathrm{p}>0,05$ & $\mathrm{p}>0,05$ \\
\hline
\end{tabular}

$n=$ número de observações; $R=$ coeficiente de correlação de Ryan-Joiner; $p=$ significância; $t=$ estatística t de Levene; $d=$ estatística de Durbin-Watson; e $F=$ razão entre variâncias .

Tabela 2. Avaliação da linearidade para as três curvas de DOR (25 a 150 ng.mL $\left.\mathrm{mL}^{-1}\right)$ em solventes.

\begin{tabular}{|c|c|c|c|}
\hline Estatística & Curva 1 & Curva 2 & Curva 3 \\
\hline \multicolumn{4}{|l|}{ Número de observações } \\
\hline$n$ & 18 & 14 & 17 \\
\hline \multicolumn{4}{|l|}{ Normalidade } \\
\hline$R$ & 0,9898 & 0,9899 & 0,9921 \\
\hline$p$ & $\mathrm{p}>0,10$ & $\mathrm{p}>0,10$ & $\mathrm{p}>0,10$ \\
\hline \multicolumn{4}{|l|}{ Homoscedasticidade } \\
\hline$t_{L}$ & $-1,139$ & 0,733 & $-1,622$ \\
\hline$p$ & $\mathrm{p}>0,05$ & $\mathrm{p}>0,05$ & $\mathrm{p}>0,05$ \\
\hline \multicolumn{4}{|l|}{ Independência } \\
\hline$d$ & 2,342 & 2,497 & 1,980 \\
\hline$p$ & $\mathrm{p}>0,10$ & $\mathrm{p}>0,10$ & $\mathrm{p}>0,10$ \\
\hline \multicolumn{4}{|l|}{ Regressão } \\
\hline$F$ & $2,091 \times 10^{+3}$ & $1,143 \times 10^{+3}$ & $2,160 \times 10^{+3}$ \\
\hline$p$ & $\mathrm{p}<0,001$ & $\mathrm{p}<0,001$ & $\mathrm{p}<0,001$ \\
\hline \multicolumn{4}{|l|}{ Desvio da linearidade } \\
\hline$F$ & 0,177 & 0,563 & 1,560 \\
\hline$p$ & $\mathrm{p}>0,05$ & $\mathrm{p}>0,05$ & $\mathrm{p}>0,05$ \\
\hline
\end{tabular}

$n=$ número de observações; $R=$ coeficiente de correlação de Ryan-Joiner; $p=$ significância; $t_{L}=$ estatística t de Levene; $d=$ estatística de Durbin-Watson; e $F=$ razão entre variâncias.

maior que a do ensaio (dia+analista), sendo atribuído o valor de zero para a variação entre ensaios ${ }^{22,23}$.

Médias de recuperação aparente aceitáveis foram atingidas na faixa de 5 a $30 \mu \mathrm{g} . \mathrm{L}^{-1}$ para ABA, DOR, EPR e IVE. Todavia, $D P R_{r}$ acima de $14,7 \%$ foram observados para DOR, EPR e IVE no nível $5 \mu \mathrm{g} . \mathrm{L}^{-1}$. Estes resultados sinalizaram exatidão e precisão do método validado na faixa de 10 a $30 \mu \mathrm{g} . \mathrm{L}^{-1}$, considerando os critérios de aceitabilidade determinados.

POLLMEIER et al..$^{33}$ obtiveram exatidão e precisão de um método para determinação de EPR em leite bovino pela análise de amostras adicionadas entre 2,3 e 51 ng. $\mathrm{mL}^{-1}$, sendo cinco a sete replicatas por nível, analisadas por dois laboratórios. Não ficou explicitado neste trabalho se as replicatas foram independentes ou simples repetições de leituras. A estimativa da precisão sob repetitividade e reprodutibilidade não foi feita adequadamente. Estes autores discutiram a precisão do método por meio do DPR calculado diretamente para os resultados obtidos por nível de concentração em cada laboratório e pelo DPR obtido para todos os resultados. SCHENCK e LAGMAN ${ }^{37}$ alcançaram médias de recuperação aparente de 85,5 a 113,8\%, com DPR entre 0,6 e 23,7\% na determinação de ABA, DOR, EPR e MOX em leite por CLEA-FL, na faixa de 1 a 30 ng. $\mathrm{mL}^{-1}$, sendo quatro replicatas de cada nível. WU et al. ${ }^{47}$ obtiveram médias de recuperação aparente de 74 a $97 \%$ para ABA e de 64 a 87\% para IVE em experimentos empregando CL-MS com amostras de fígado suíno adicionadas entre 5 e $100 \mu g . \mathrm{kg}^{-1}$, sendo triplicata de cada nível. Os valores de desvios padrão reportados situaram-se entre 0,3 e 6,5 $\mu \mathrm{g} . \mathrm{kg}^{-1}$ para ABA e entre 0,4 e 7,2 $\mu$ g. $\mathrm{kg}^{-1}$ para IVE. ROUDAUT ${ }^{34}$ estimou adequadamente exatidão e precisão de um método para ensaio de ABA, DOR, IVE e MOX em fígado bovino por CLAE-FL. Na faixa de 15 a $100 \mu g . \mathrm{kg}^{-1}$ este autor obteve médias de recuperação aparente variando de 77,5 a $90,8 \%$, com $D P R_{r}$ e $D P R_{R}$ entre 3,8 e $9,4 \%$ 
Tabela 3. Avaliação da linearidade para as três curvas de EPR ( 25 ng.mL $\mathrm{mL}^{-1}$ a $\left.150 \mathrm{ng} \cdot \mathrm{mL}^{-1}\right)$ em solventes.

\begin{tabular}{|c|c|c|c|}
\hline Estatística & Curva 1 & Curva 2 & Curva 3 \\
\hline \multicolumn{4}{|l|}{ Número de observações } \\
\hline$n$ & 17 & 14 & 18 \\
\hline \multicolumn{4}{|l|}{ Normalidade } \\
\hline$R$ & 0,9846 & 0,9909 & 0,9836 \\
\hline$p$ & $\mathrm{p}>0,10$ & $\mathrm{p}>0,10$ & $\mathrm{p}>0,10$ \\
\hline \multicolumn{4}{|l|}{ Homoscedasticidade } \\
\hline$t_{L}$ & 0,329 & $-1,579$ & 0,520 \\
\hline$p$ & $\mathrm{p}>0,05$ & $\mathrm{p}>0,05$ & $\mathrm{p}>0,05$ \\
\hline \multicolumn{4}{|l|}{ Independência } \\
\hline$d$ & 1,950 & 2,802 & 1,212 \\
\hline$p$ & $\mathrm{p}>0,10$ & $\mathrm{p}>0,10$ & $\mathrm{p}>0,10$ \\
\hline \multicolumn{4}{|l|}{ Regressão } \\
\hline$F$ & $3,117 \times 10^{+3}$ & $1,669 \times 10^{+3}$ & $2,062 \times 10^{+3}$ \\
\hline$p$ & $\mathrm{p}<0,001$ & $\mathrm{p}<0,001$ & $\mathrm{p}<0,001$ \\
\hline \multicolumn{4}{|l|}{ Desvio da linearidade } \\
\hline$F$ & 2,473 & 2,125 & 2,930 \\
\hline$p$ & $\mathrm{p}>0,05$ & $\mathrm{p}>0,05$ & $\mathrm{p}>0,05$ \\
\hline
\end{tabular}

$n=$ número de observações; $R=$ coeficiente de correlação de Ryan-Joiner; $p=$ significância; $t_{L}=$ estatística t de Levene; $d=$ estatística de Durbin-Watson; e $F=$ razão entre variâncias.

Tabela 4. Avaliação da linearidade para as três curvas de IVE (25 a 150 ng.mL $\mathrm{mL}^{-1}$ ) em solventes.

\begin{tabular}{|c|c|c|c|}
\hline Estatística & Curva 1 & Curva 2 & Curva 3 \\
\hline \multicolumn{4}{|l|}{ Número de observações } \\
\hline$n$ & 14 & 15 & 16 \\
\hline \multicolumn{4}{|l|}{ Normalidade } \\
\hline$R$ & 0,9763 & 0,9889 & 0,9710 \\
\hline$p$ & $\mathrm{p}>0,10$ & $\mathrm{p}>0,10$ & $\mathrm{p}>0,10$ \\
\hline \multicolumn{4}{|l|}{ Homoscedasticidade } \\
\hline$t_{L}$ & $1,322 \times 10^{-14}$ & $-0,625$ & $-1,592$ \\
\hline$p$ & $\mathrm{p}>0,05$ & $\mathrm{p}>0,05$ & $\mathrm{p}>0,05$ \\
\hline \multicolumn{4}{|l|}{ Independência } \\
\hline$d$ & 1,455 & 1,719 & 2,114 \\
\hline$p$ & $\mathrm{p}>0,10$ & $\mathrm{p}>0,10$ & $\mathrm{p}>0,10$ \\
\hline \multicolumn{4}{|l|}{ Regressão } \\
\hline$F$ & $5,322 \times 10^{+3}$ & $6,445 \times 10^{+2}$ & $2,237 \times 10^{+3}$ \\
\hline$p$ & $\mathrm{p}<0,001$ & $\mathrm{p}<0,001$ & $\mathrm{p}<0,001$ \\
\hline \multicolumn{4}{|l|}{ Desvio da linearidade } \\
\hline$F$ & 1,496 & 2,256 & 0,580 \\
\hline$p$ & $\mathrm{p}>0,05$ & $\mathrm{p}>0,05$ & $\mathrm{p}>0,05$ \\
\hline
\end{tabular}

$n=$ número de observações; $R=$ coeficiente de correlação de Ryan-Joiner; $p=$ significância; $t_{L}=$ estatística t de Levene; $d=$ estatística de Durbin-Watson; e $F=$ razão entre variâncias.

e entre 4,05 e 9,61\%, respectivamente. As condições experimentais, assim como os critérios de aceitabilidade estipulados não foram discutidos nos trabalhos supracitados.

O limite de detecção experimental do método foi estabelecido como $5 \mu \mathrm{g}$. $\mathrm{L}^{-1}$, visto que as quatro avermectinas foram detectadas com médias de sinal/ruído $\geq 3$ nas amostras adicionadas neste nível. O limite de quantificação para estes compostos, correspondente ao menor nível de concentração no qual os experimentos indicaram exatidão e precisão do método, foi de $10 \mu \mathrm{g} \cdot \mathrm{L}^{-1}$. A transição entre as faixas de detecção e quantificação do método pode ser observada pela distribuição dos resultados de recuperação aparente individuais obtidos para amostras adicionadas (Figura 5). Limites inferiores aos alcançados neste processo de validação foram reportados por autores que adotaram como critério a relação sinal/ruído obtida para replicatas de amostras brancas. POLLMEIER et al. ${ }^{33}$ obtiveram limite de detecção de 0,25 ng.mL ${ }^{-1}$ e limite de quantificação de 2 ng.mL $\mathrm{mL}^{-1}$ para EPR em leite por CLAE-FL. Limite de detecção idêntico ao estabelecido por este trabalho foi publicado por WU et al. ${ }^{47}$ para ABA e IVE. No entanto, nada foi apresentado com relação aos limites de quantificação. ROUDAUT ${ }^{34}$ estabeleceu limites de

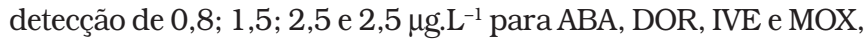
respectivamente, utilizando amostras brancas de fígado bovino e sistema CLAE-FL. Limite de quantificação de $7,5 \mu \mathrm{g} . \mathrm{kg}^{-1}$ foi apresentado por este autor, mas nenhuma descrição do experimento e critérios para determinação deste parâmetro foi feita. Embora superiores, os limites apresentados neste trabalho são certamente mais realísticos, pois foram estabelecidos sob critérios mais rigorosos em experimentos de recuperação com amostras de leite bovino adicionadas de avermectinas.

Considerando um limite máximo de resíduo de $10 \mu \mathrm{g} . \mathrm{L}^{-1}$ para as avermectinas pesquisadas, $C C \alpha$ de 12,$8 ; 12,9 ; 12,6$ e 

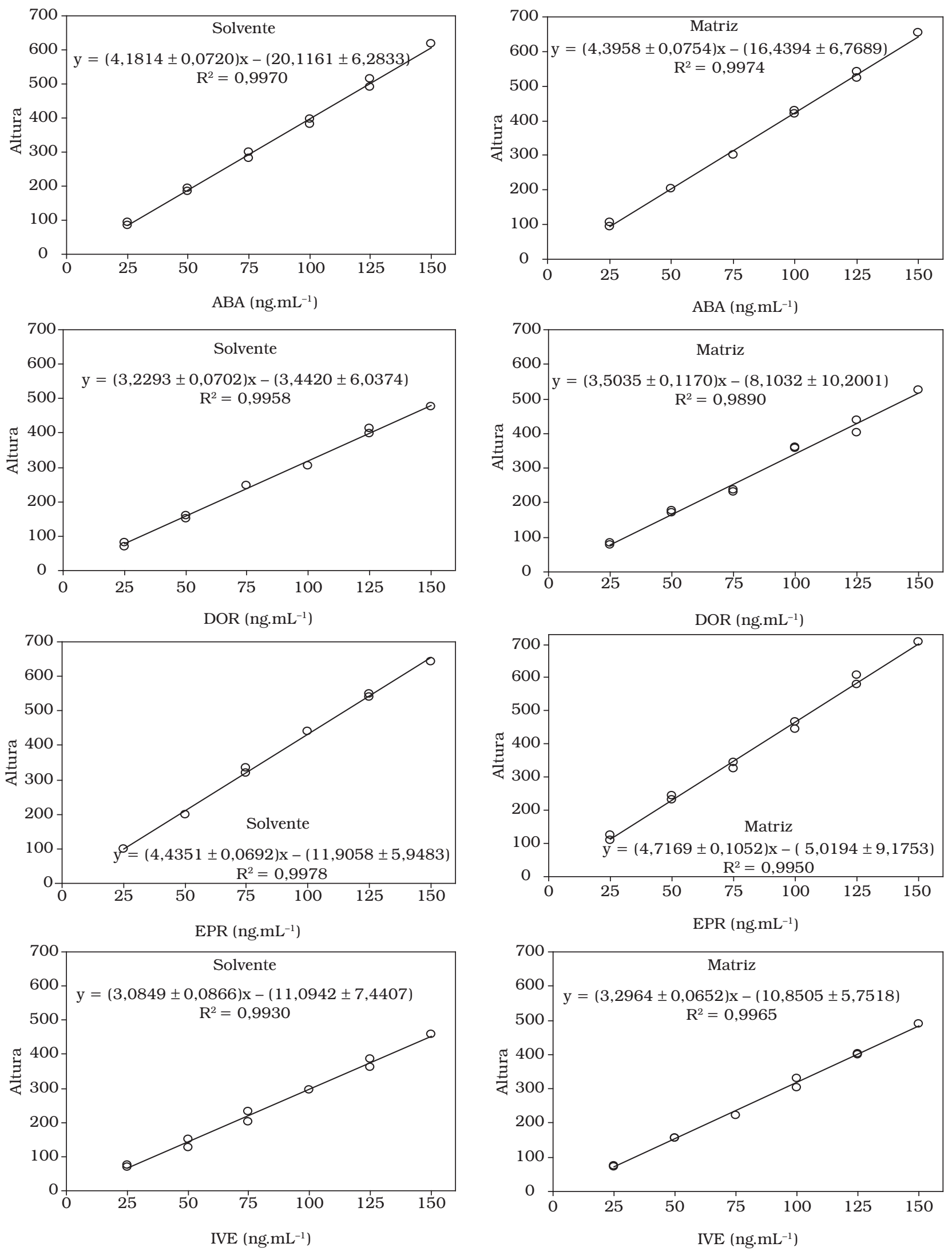

Figura 3. Curvas de calibração dos analitos no solvente e na matriz obtidas para ABA, DOR, EPR e IVE nos ensaios de avaliação de efeitos de matriz, na faixa de 25 a 150 ng. $\mathrm{mL}^{-1}$, com respectivas equações e coeficientes de determinação. $\mathrm{y}=$ resposta em altura dos picos; $\mathrm{x}=$ concentração de avermectina em ng. $\mathrm{mL}^{-1}$; e $\mathrm{R}^{2}=$ coeficiente de determinação. 
Tabela 5. Comparações entre as interseções e inclinações das curvas dos analitos no solvente e na matriz para ABA, DOR, EPR e IVE (25 a 150 ng. $\mathrm{mL}^{-1}$ ).

\begin{tabular}{ccccc}
\hline Estatística & ABA & DOR & EPR & IVE \\
\hline Comparação da interseção das curvas dos analitos no solvente e na matriz & & \\
$t_{a}$ & 0,360 & 0,351 & 0,556 & 0,023 \\
$p$ & 0,72 & 0,73 & 0,59 & 0,98 \\
$G L$ & 17 & 17 & 17 & 16 \\
Comparação da inclinação das curvas dos analitos no solvente e na matriz & & 1,842 \\
$t_{b}$ & 1,946 & 1,873 & 2,090 \\
$P$ & 0,07 & 0,08 & 0,05 & 0,08 \\
$G L$ & 17 & 17 & 17 & 16 \\
\hline$t_{a}=$ estatística t para contrastes entre interseções; $t_{b}=$ estatística t para contrastes entre inclinações; $p=$ significância; $G L=$ graus de liberdade $\left(n_{s}+n_{m}-4\right)$, sendo $n_{s}$ número de pontos da
\end{tabular}
curva em solvente e $n_{m}$ número de pontos da curva em matriz.

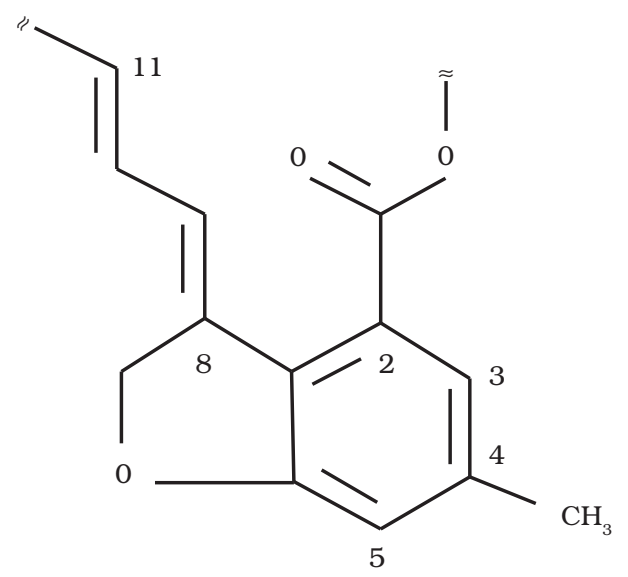

Derivado fluorescente das avermectinas.

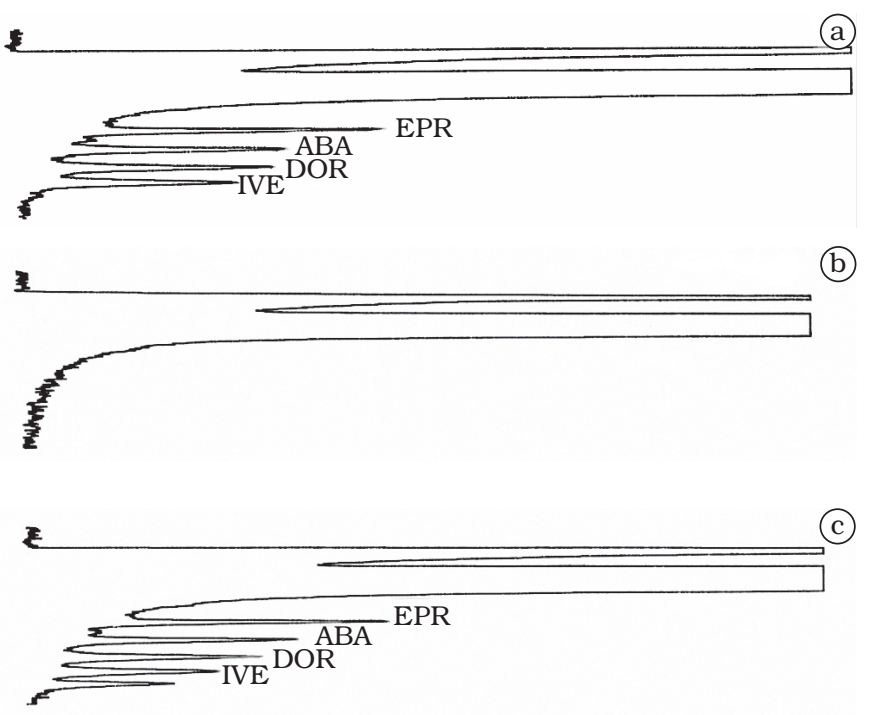

Figura 4. Estrutura química do derivado fluorescente das avermectinas e cromatogramas típicos obtidos por CLAE-FL. a = solução padrão de avermectinas de 150 ng. $\mathrm{mL}^{-1} ; \mathrm{b}=$ amostra de leite bovino branca; e $\mathrm{c}=$ amostra de leite bovino adicionada de avermectinas em $30 \mu \mathrm{g} \cdot \mathrm{L}^{-1}$.

13,7 $\mu$ g. $\mathrm{L}^{-1}$ e $C C \beta$ de 15,$6 ; 15,9 ; 15,1$ e $17,4 \mu \mathrm{g} . \mathrm{L}^{-1}$ foram estimados para ABA, DOR, EPR e IVE, respectivamente. Não foram encontrados trabalhos na literatura sobre a determinação de $C C \alpha$ e $C C \beta$ para as avermectinas estudadas em leite, embora a estimativa destes limites seja recomendada ${ }^{15}$. A importância destes parâmetros fundamenta-se no fato de que, se obtidos resultados de concentração menores que os valores estabele- cidos para $C C \alpha$, as amostras podem ser declaradas como conformes ou com analitos em concentrações inferiores ao limite máximo de resíduos estabelecido, com um nível de confiança de $(1-\alpha)$. No caso de resultados de concentração maiores ou iguais aos valores estimados para $C C \beta$, as amostras podem ser declaradas como não-conformes ou com analito presente em concentrações superiores ao limite máximo de resíduos, com 
Tabela 6. Médias de recuperação aparente e desvios padrão relativos, sob condições de repetitividade e reprodutibilidade parcial, obtidos para amostras de leite bovino adicionadas de ABA e DOR em diferentes níveis de concentração.

\begin{tabular}{|c|c|c|c|c|c|c|}
\hline \multirow[t]{2}{*}{ Concentração ( $\mu$ g. $\left.\mathrm{L}^{-1}\right)$} & \multicolumn{3}{|c|}{ ABA } & \multicolumn{3}{|c|}{ DOR } \\
\hline & $\bar{R}(\%)$ & $D P R_{r}(\%)$ & $D P R_{R}(\%)$ & $\bar{R}(\%)$ & $D P R_{r}(\%)$ & $D P R_{R}(\%)$ \\
\hline 5 & 101,8 & 13,9 & 14,3 & 86,2 & 21,3 & 21,4 \\
\hline 10 & 98,9 & 6,7 & 9,6 & 91,9 & 7,9 & 12,0 \\
\hline 15 & 98,1 & 9,5 & 11,5 & 90,1 & 11,2 & 11,7 \\
\hline 20 & 101,4 & 5,8 & 8,6 & 98,0 & 4,7 & 9,1 \\
\hline 30 & 99,9 & 4,1 & 8,0 & 96,6 & 3,6 & 8,7 \\
\hline
\end{tabular}

$\overline{\bar{R}}=$ média de recuperação aparente; $D P R_{r}=$ desvio padrão relativo de repetitividade; $D P R_{R}=$ desvio padrão relativo de reprodutibilidade parcial. Critérios de aceitabilidade para $\bar{R}: 70$ a $110 \%$ (para amostras adicionadas $>1$ a $10 \mu$ g. $\mathrm{L}^{-1}$ ), 80 a $110 \%$ (para amostras adicionadas $\geq 10 \mu$ g. $\mathrm{L}^{-1}$ ). Critério de aceitabilidade para $D P R_{r}: \leq 14,7 \%$. Critério de aceitabilidade para $D P R_{R}$ : $\leq 22 \%$.

Tabela 7. Médias de recuperação aparente e desvios padrão relativos, sob condições de repetitividade e reprodutibilidade parcial, obtidos para amostras de leite bovino adicionadas de EPR e IVE em diferentes níveis de concentração.

\begin{tabular}{|c|c|c|c|c|c|c|}
\hline \multirow[t]{2}{*}{ Concentração $\left(\mu \mathrm{g} \cdot \mathrm{L}^{-1}\right)$} & \multicolumn{3}{|c|}{ EPR } & \multicolumn{3}{|c|}{ IVE } \\
\hline & $\bar{R}(\%)$ & $D P R_{r}(\%)$ & $D P R_{R}(\%)$ & $\bar{R}(\%)$ & $D P R_{r}(\%)$ & $D P R_{R}(\%)$ \\
\hline 5 & 81,2 & 20,2 & 20,2 & 84,0 & 16,7 & 19,5 \\
\hline 10 & 92,7 & 8,7 & 9,0 & 94,8 & 10,7 & 14,7 \\
\hline 15 & 90,6 & 6,7 & 7,4 & 87,2 & 9,0 & 13,9 \\
\hline 20 & 94,0 & 8,0 & 8,8 & 94,6 & 6,9 & 10,2 \\
\hline 30 & 96,9 & 5,0 & 8,0 & 92,1 & 4,4 & 11,0 \\
\hline
\end{tabular}

$\overline{\bar{R}}=$ média de recuperação aparente; $D P R_{r}=$ desvio padrão relativo de repetitividade; $D P R_{R}=$ desvio padrão relativo de reprodutibilidade parcial. Critérios de aceitabilidade para $\bar{R}: 70$ a $110 \%$ (para amostras adicionadas $>1$ a $10 \mu \mathrm{g} . \mathrm{L}^{-1}$ ), 80 a $110 \%$ (para amostras adicionadas $\geq 10 \mu \mathrm{g} . \mathrm{L}^{-1}$ ). Critério de aceitabilidade para $D P R_{r}: \leq 14,7 \%$. Critério de aceitabilidade para $D P R_{R}$ : $\leq 22 \%$.

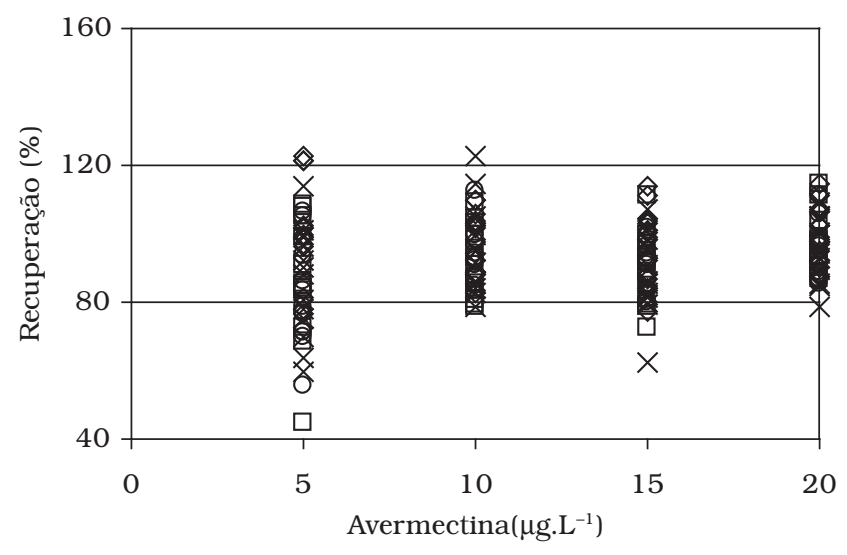

Figura 5. Distribuição dos resultados individuais de recuperação aparente obtidos para amostras adicionadas entre 5 e $20 \mu \mathrm{g} . \mathrm{L}^{-1}$, incluindo os níveis correspondentes aos limites de detecção $\left(5 \mu \mathrm{g} . \mathrm{L}^{-1}\right)$ e quantificação $\left(10 \mu \mathrm{g} \cdot \mathrm{L}^{-1}\right) . \diamond=\mathrm{ABA}, \square=\mathrm{DOR}, \mathrm{O}=\mathrm{EPR}, \times=$ IVE.

um nível de confiança de $(1-\beta)^{15}$. Há uma faixa de incerteza estatística entre os valores de $C C \alpha$ e $C C \beta$ e a aplicação prática destes parâmetros depende de decisões políticas que envolvem a proteção do consumidor e do produtor de alimentos ${ }^{1}$. A 95\% de confiança, para substâncias com limite máximo de resíduos definido, em $C C \alpha$ a proporção de resultados falsos não-conformes (erro $\alpha$ ) será de $5 \%$, mas de falsos conformes (erro $\beta$ ) será de $50 \%$. Por outro lado, em CC $\beta$ a proporção de amostras falsamente declaradas não-conformes será muito baixa, e a proporção de amostras verdadeiramente nãoconformes apresentarem um resultado conforme será igual a $5 \%$. Assim, CC $\beta$ deverá ser empregado se o método aqui validado for utilizado como um método de triagem, concebido para selecionar, dentro de um grande número de amostras, os resultados potencialmente não-conformes e evitar a obtenção de resultados falsos conformes ${ }^{15,46}$. Por outro lado, se este método fosse utilizado com propósitos confirmatórios, nos quais a identificação inequívoca da presença de uma substância é pretendida, tanto $C C \alpha$ como $C C \beta$ teriam aplicação ${ }^{15}$ e o método seria capaz de identificar as avermectinas em 95\% dos casos em $C C \beta$ e em $50 \%$ de todos os casos em $C C \alpha$.

\section{Conclusões}

O procedimento proposto foi adequado para validação intralaboratorial de métodos. Os parâmetros de desempenho do método aqui validado indicaram adequação para uso nas atividades de monitoramento de resíduos de avermectinas em leite bovino pelo PNCRB do MAPA, atendendo aos limites regulamentados pelo BRASIL ${ }^{6}$ e sugeridos pelo CODEX ALIMENTARIUS ${ }^{10}$

\section{Referências bibliográficas}

1. ANTIGNAC, J. P. et al. Validation of analytical methods based on mass spectrometric detection according to the "2002/657/EC" European decision: guideline and application. Anal. Chim. Acta, v. 483, n. 1, p. 325-334, 2003.

2. ARENA, J. P. et al. The mechanism of action of avermectins in Caenorhabditis elegans: correlation between activation of glutamate-sensitive chloride current, membrane binding, and biological activity. J. Parasitol., v. 81, n. 2, p. 286-294, 1995.

3. ARMITAGE, P.; BERRY, G. Statistical methods in medical research. Oxford: Blackwell Science Ltd., 1994. 620 p.

4. BARRET, V.; LEWIS, T. Outliers in statistical data. 3 ed. New York: John Wiley, 1994. 604 p.

5. BELSLEY, D. A.; KUH, E.; WELSCH, R. E. Regression diagnostics: identifying influential data and sources of collinearity. New York: Wiley, 1980. 292 p. 
6. BRASIL. Ministério da Agricultura, Pecuária e Abastecimento. Portaria número 50 de 20 de fevereiro de 2006. Aprova os Programas de Controle de Resíduos em Carne, Leite, Mel, Ovos e Pescado do exercício de 2006. Diário Oficial da União, Brasília, DF, 03 março 2006, Seção 1, p. 15.

7. BROWN, M. B.; FORSYTHE, A. B. Robust tests for the equality of variances. J. Am. Stat. Assoc., v. 69, n. 346, p. 364-367, 1974.

8. BURKE, S. Missing values, outliers, robust statistics \& nonparametric methods. LC • GC Europe Online Supplement, January, p. 19-24, 2001. New York: Advanstar. Disponível em: < http://www. lcgceurope.com/ lcgceurope/Statistics $+\% 26+$ Data+Analysis $>$. Acesso em: 28 de abril de 2005.

9. CAMPBELL, W. C. et al. Ivermectin: a potent new antiparasitic agent. Science, v. 221, n. 4613, p. 823-828, 1983.

10. CODEX ALIMENTARIUS. Codex Alimentarius Comission. Toxicological evaluation of certain veterinary drug residues in food. Disponível em: < http://www.codexalimentarius. net/web/ jecfa.jsp>. Acesso em: 28 de abril de 2005.

11. DRAPER, N.; SMITH, H. Applied regression analysis. New York: Wiley. 1998. 706 p.

12. DUCE, I. R.; SCOTT, R. H. Actions of dihydroavermectin Bla on insect muscle. Br. J. Pharmac., v. 85, n. 2, p. 395-401, 1985.

13. DURBIN, J.; WATSON, G. S. Testing for serial correlation in least squares regression ii. Biometrika, v. 38, n. 1-2, p. 159-178, 1951.

14. EAL (European Cooperation for Accreditation of Laboratories). EAL-P11. Validation of test methods: general principles and concepts. Paris: EAL, 1997. 13 p.

15. EC (European Commission). Commission decision 2002/657/ EC of 12 August 2002. Implementing Council Directive 96/23/ EC concerning performance of analytical methods and the interpretation of results. Official Journal of the European Communities, Brussels, 2002, L 221/8.

16. EURACHEM. The fitness for purpose of analytical methods, a laboratory guide to method validation and related topics. Teddington: LGC, 1998. $61 \mathrm{p}$.

17. GRUBBS, F. Procedures for detecting outlying observations in samples. Technometrics, v. 11, n. 1, p. 1-21, 1969.

18. HORWITZ, W. Evaluation of analytical methods used for regulation of food and drugs. Anal. Chem., v. 54, n. 1, p. 67A-76A, 1982.

19. HORWITZ, W. Protocol for the design, conduct and interpretation of method-performance studies. Pure Appl. Chem., v. 67, n. 2, p. 331-343, 1995.

20. ICH (International Conference on Harmonization of Technical Requirements for Registration of Pharmaceuticals for Human Use). Validation of analytical procedures: methodology. Geneva: ICH/IFPMA, 1996. 8 p.

21. INMETRO (Instituto Nacional de Metrologia, Normalização e Qualidade Industrial). DOQ-CGCRE-008. Orientações sobre validação de métodos de ensaios químicos. Rio de Janeiro: INMETRO, 2003. 35 p.

22. ISO (International Standards Organization). ISO 5725-1. Accuracy (trueness and precision) of measurement methods and results - Parts 1, 2, 3, 4 and 6. Geneva: ISO, 1994.

23. ISO (International Standards Organization). ISO 5725-5. Accuracy (trueness and precision) of measurement methods and results - Part 5. Geneva: ISO, 1998. 56 p.
24. ISO (International Standards Organization). ISO 11843-1. Capability of detection - Part 1: Terms and definitions. Geneva: ISO, 1997. $10 \mathrm{p}$.

25. ISO (International Standards Organization). ISO 11843-2. Capability of detection - Part 2: Methodology in the linear calibration case. Geneva: ISO, 2000. 24 p.

26. ISO (International Standard Organization). ISO/IEC 17025. General requirements for the competence of testing and calibration laboratories. Geneva: ISO, 2005. 28 p.

27. KUTTATHARMMAKUL, S.; MASSART, D.L.; SMEYERSVERBEKE, J. Comparison of alternative measurement methods. Anal. Chim. Acta, v. 391, n. 2, p. 203-225, 1999.

28. LEVENE, H. Robust tests for equality of variances. In: OLKIN, I.; GHURYE, S.G.; HOEFFDING, W.; MADOW, W.G.; MANN, H.B. (Ed.) Contributions to probability and statistics. Stanford: Stanford University Press, 1960. p. 278-292.

29. MAROTO, A. et al. Estimating uncertainties of analytical results using information from the validation process. Anal. Chim. Acta v. 391, n. 2, p. 173-185, 1999.

30. MC KELLAR, Q. A. Ecotoxicology and residues of anthelmintic compounds. Vet. Parasitol., v. 72, n. 3, p. 413-435, 1997.

31. MEYER, P. C.; ZUND, R. E. Statistical methods in analytical chemistry. New York: John Wiley \& Sons, 1993. p. 81-134.

32. NATA (National Association of Testing Authorities - Australia). Technical note 17. Format and content of test methods and procedures for validation and verification of chemical test methods. Sydney: NATA, 1997. 8 p.

33. POLLMEIER, M. et al. High-performance liquid chromatography assay for the determination of a semisynthetic avermectin analog (eprinomectin) in bovine milk at parts per billion levels - method development and validation. J. Chromatogr. B, v. 772, n. 1 , p. 99-105, 2002.

34. ROUDAUT, B. Multiresidue method for the determination of avermectin and moxidectin residues in the liver using HPLC with fluorescence detection. Analyst, v. 123, n. 12, p. 2541-2544, 1998.

35. RYAN, T. A.; JOINER, B. L. Normal probability plots and tests for normality. The State College: Pennsylvania State University, 1976. $15 \mathrm{p}$.

36. SALISBURY, C. D. C. Modified method for the determination of ivermectin residues in animal tissues. J. AOAC Int., v. 76, n. 5, p. 1149-1151, 1993.

37. SCHENCK, F. J.; LAGMAN, L. H. Multiresidue determination of abamectin, doramectin, ivermectin, and moxidectin in milk using liquid chromatography and fluorescence detection. J. AOAC Int., v. 82, n. 6, p. 1340-1344, 1999.

38. SNEDECOR, G. W.; COCHRAN, W. G. Statistical methods. Ames: Iowa State University, 1989. 503 p.

39. SOUZA, S. V. C.; JUNQUEIRA, R. G. A procedure to assess linearity by ordinary least squares method. Anal. Chim. Acta v. 552, n. 1-2, p. 25-35, 2005.

40. SOUZA, S. V. C. et al.Determinação de resíduos de avermectinas em fígado bovino por cromatografia líquida de alta eficiência. Ciênc. Tecnol. Aliment., v. 23, n. 1, p. 54-58, 2003.

41. THOMPSON, M. Recent trends in inter-laboratory precision at ppb and sub-ppb concentrations in relation to fitness for purpose criteria in proficiency testing. Analyst, v. 125, n. 3, p. 385-386, 2000 . 
42. THOMPSON, M.; ELLISON, S.L.R.; WOOD, R. Harmonized guidelines for single-laboratory validation of methods of analysis. Pure Appl. Chem., v. 74, n. 5, p. 835-855, 2002.

43. TURNER, M. J.; SCHAEFFER, J. M. Mode of action of ivermectin. In: CAMPBELL, W.C. (Ed.) Ivermectin and abamectin. New York: Springer-Verlag, 1989. p. 73-88.

44. VAlenZUela, A. I. et al. Comparison of various liquid chromatographic methods for the analysis of avermectins residues in citrus fruits. J. Chromatogr. A, v. 918, n. 1, p. 59-65, 2001.

45. VAN LOCO, J.; BEERNAERT, H. In: PROCEEDINGS OF EUROPEAN FOOD CHEMISTRY, 12, 2003, Brugges, Belgium.
Proceedings... Brugges: European Food Chemistry, 2003. p. 91-94.

46. VAN OVERMEIRE, I. et al. Interpretation of CALUX results in view of the EU maximal TEQ level in milk. Talanta, v. 63, n. 5, p. 1241-1247, 2004.

47. WU, Z. et al. Multi-residue analysis of avermectins in swine liver by immunoaffinity extraction and liquid chromatographymass spectrometry. J. Chromatogr. B, v. 755, n. 1, p. 361-366, 2001. 